\title{
Taxonomías web de clubes de fútbol argentinos
}

\section{María Caminotti}

Bibliotecaria documentalista.

E-mail: dhubi@fahce.unlp.edu.ar

\section{Edgardo Stubbs}

Licenciado en bibliotecología y documentación.

E-mail: dhubi@fahce.unlp.edu.ar

\section{José Balparda}

Bibliotecario documentalista.

E-mail: dhubi@fahce.unlp.edu.ar

\section{Ana Martinez}

Licenciada en bibliotecología y documentación.

E-mail: ammarti@speedy.com.ar

\section{Resumen}

Se analizaron las taxonomías web navegacionales de clubes de fútbol argentinos, con el propósito de identificar sus taxones y las categorías subyacentes, así como elaborar una taxonomía común, basada en las categorías fundamentales recomendadas por el Classification Research Group, para comparar las taxonomías analizadas y comprobar si pueden ser desarrolladas mediante el método del análisis por facetas. El análisis de los taxones muestra una tendencia a usar términos en inglés y nombres propios o específicos relacionados con aspectos emocionales e identificatorios de cada club, que puede requerir cambios en la aplicación tradicional de las normas de control de vocabulario. El uso de las categorías fundamentales permitiría un análisis más exhaustivo de la información a colocar en el sitio web y un mejor diseño de la taxonomía, siendo una herramienta útil para el bibliotecario interesado en este tipo de recurso.

\section{Palabras clave}

Clasificación facetada. Sitios de fútbol de clabes argentinos. Vocabulario controlado. Lenguajes documentarios.

\section{Web taxonomies of Argentinean soccer clubs}

\begin{abstract}
The navigable taxonomies web of Argentinean soccer clubs have been analyzed for the purpose of identifying their taxonomies and inherent categories, as well as elaborating a common taxonomy, based on fundamental categories recommended by Classification Research Group, in order to compare the taxonomies analyzed and demonstrate whether they can be developed by a method of facet analysis. The analysis of taxonomic elements show a tendency to use English terms and proper names or specific terms related to emotional and identifying aspects of the norms of vocabulary control. The use of fundamental categories will allow a more exhaustive analysis of information to be put in the web site and a better design of taxonomy, which is a useful tool for the librarian interested in this type of resource.
\end{abstract}

\section{Keywords}

Faceted classification. Sites of Argentine soccer clubs. Controlled vocabularies. Documentary languages.

\section{INTRODUCCIÓN}

Como es sabido, el método de análisis por facetas ha sido empleado en el diseño de numerosos sistemas de organización del conocimiento, incluyendo sistemas de clasificación, tesauros y epígrafes (1-2). Existen dos fuentes principales para este método. Por un lado, el bibliotecario indio Shiyali Ramamrita Ranganathan (3) postuló cinco categorías fundamentales (Personalidad, Materia, Energía, Espacio y Tiempo) aplicables -según Ranganathan- a todos los campos del conocimiento.

Por otro lado, el Classification Research Group (CRG) de Gran Bretaña ha postulado que no es posible aplicar las mismas categorías fundamentales a todos los campos del conocimiento. Por el contrario, el CRG ha recomendado establecer las categorías fundamentales particulares para cada campo, después de haber analizado la información pertinente (4). Sin embargo, luego de años de investigación y aplicación a diferentes temáticas, los miembros del CRG han utilizado un conjunto de categorías o facetas fundamentales, a las que nos referiremos en adelante como las categorías del CRG (56). Esas categorías son las siguientes:

Entidades, cosas, objetos según sus características

- Entidades abstractas (ideas, disciplinas)

- Entidades que ocurren en la naturaleza (radiación, nubes, ríos)

- Entidades u organismos vivos (bacterias, virus, mamíferos)

- Artefactos hechos por el hombre (artículos manufacturados, objetos de arte)

- Atributos: propiedades, cualidades, estados, condiciones (temperatura, color, confiabilidad, tamaño)

- Sustancias materiales o constituyentes (minerales, madera, cuero, plásticos, drogas)

- Partes o componentes (tipos, timones, partes del cuerpo, techos, pisos)

- Entidades completas o complejas (motores, barcos, edificios, escuelas) 
Entidades, cosas, objetos según su función

- Agentes: individuos, personal, organizaciones (artistas, marineros, doctores, asociaciones profesionales)

- Agentes: equipamiento, aparatos (maquinaria, computadoras, respiradores, lavavajillas)

- Pacientes (víctimas, beneficiarios, audiencias)

- Productos finales (alimentos, residuos, resultados de una investigación)

Acciones, actividades

- Procesos o funciones (desarrollo, enfermedades, pensamiento)

- Operaciones (enseñanza, curación, gerenciamiento)

Espacio

Tiempo

Por otra parte, hoy en día se reconoce que dentro de una organización cualquiera, sea una empresa, una agencia de gobierno, una organización no gubernamental, etc., la información tiene un valor tangible, que incluso puede medirse en pesos y centavos. El acceso efectivo a la información, por lo tanto, resulta imprescindible. Una de las herramientas que garantizan este acceso efectivo es la taxonomía corporativa u organizacional.

Según Gilchrist y Kibby (7), la taxonomía de una organización proporciona un mapa de conocimiento que facilita tanto la navegación, como el acceso a su capital intelectual, conecta a las personas con la información contenida en los documentos y a unas personas con otras personas dentro de la organización, al mismo tiempo que puede aportar un valor adicional si se extiende hacia fuera, es decir a la extranet de la organización. Con esto en mente, han definido la taxonomía corporativa u organizacional como "una correlación de los diferentes lenguajes funcionales usados por la empresa, que proporcionan herramientas tales como las ayudas de navegación, las autoridades para etiquetar los documentos y otros objetos de información, soportes para motores de búsqueda, mapas de conocimiento y, posiblemente, una base de conocimiento en todo sentido".

En el mismo sentido, Conway y Sligar (8) han definido tres tipos de taxonomías corporativas:

- La taxonomía descriptiva o vocabulario controlado que permite describir el contenido de los documentos en los metadatos, es decir lo que Gilchrist y Kibby denominan "autoridades para etiquetar los documentos y otros objetos de información".
- La taxonomía navegacional que apunta a facilitar la búsqueda de información mediante la navegación. Los términos, en este caso, están ordenados en categorías y por lo tanto organizados en forma sistemática. Un ejemplo de esto es el mapa del sitio web de la organización.

- La taxonomía para gestión de datos es un tipo de vocabulario que se utiliza para registrar las transacciones de negocios en formularios, planillas u otros documentos operativos y facilitar tanto la elaboración de informes, como la minería de datos, evitando el aislamiento y el solapamiento de los datos. Es un vocabulario compartido entre el personal, los clientes y proveedores de la organización. Según Conway y Sligar (8) se puede incluir sin dificultad en la taxonomía descriptiva.

En otras palabras, la meta de una taxonomía corporativa no es solamente proporcionar una lista de términos autorizados para usar en la búsqueda de información, sino crear una red semántica basada en las necesidades de la organización, tomando en cuenta tanto la información como las personas que la requieren y las necesidades de la propia organización.

Si bien en años recientes se ha revalorado el análisis por facetas para el diseño de taxonomías web $(9-11)$, en Argentina no hay experiencias publicadas en el diseño de taxonomías web para clubes de fútbol basadas en el análisis por facetas. Sin embargo, las categorías del CRG han podido identificarse como subyacentes a las taxonomías web de dichos clubes (12).

En consecuencia, los objetivos de este trabajo fueron:

1. Analizar un cierto número de taxonomías web navegacionales de clubes de fútbol argentinos, con el fin de identificar los taxones y seleccionar los términos preferidos.

2. Elaborar una taxonomía común para clubes de fútbol, ordenando los términos seleccionados en el punto anterior según las categorías del CRG.

3. Evaluar las taxonomías particulares analizadas en el punto 1, comparándolas con la taxonomía común mencionada en el punto 2 .

\section{METODOLOGÍA}

\section{Identificación de taxones y selección de términos preferidos}

Para cumplir con el Objetivo 1, se estudiaron las taxonomías navegacionales de 9 clubes de fútbol argentinos de primera división, cuyos sitios web estaban 
disponibles en el período comprendido entre 1 de julio de 2004 y el 30 de junio de 2005. Los clubes fueron los siguientes:

a. Club Gimnasia y Esgrima de La Plata

b. Club Atlético Independiente

c. Club Atlético San Lorenzo de Almagro

d. Club Atlético Vélez Sarfield

e. Club Estudiantes de La Plata

f. Racing Club

g. Club Atlético River Plate

h. Club Atlético Boca Juniors

i. Club Atlético Rosario Central

Las taxonomías analizadas fueron aquellas pertenecientes a los sitios web (extranet), no a la Intranet de cada club, de manera que estaban orientadas al público en general y no al personal de la organización.

De cada taxonomía particular, se identificaron y seleccionaron los taxones de acuerdo con los siguientes criterios:

- Garantía documental: sólo los taxones mencionados al menos en una de las 9 taxonomías fueron tomados en cuenta para la taxonomía común.

- Nivel de especificidad: sólo los taxones genéricos, que podían ser aplicados a todos los clubes de fútbol, fueron tomados en cuenta para la taxonomía común.

- Terminología: los términos usados en la taxonomía común debían ser aceptables para cualquier club de fútbol. Por lo tanto, expresiones como pasión boquense, pueblo canalla, nace la academia, etc., no fueron seleccionados para la taxonomía común, por ser específicos de un determinado club. En adición, cuando los términos eran sinónimos, como plantel y equipo, se eligió sólo uno como término preferido.

Es importante remarcar que se trataba de taxonomías de clubes de fútbol, no del fútbol en sí, es decir fueron taxonomías de las organizaciones, no del deporte. Por este motivo, algunos términos como gol, pelota u otros artefactos o acciones inherentes al juego no aparecen como taxones de estos sitios web

\section{Taxonomía común}

Todos los taxones seleccionados en el paso anterior fueron considerados aislados.
Para cumplir con el Objetivo 2, se organizaron los aislados según las categorías del CRG mencionadas en la Introducción, con lo cual esos aislados pasaron a ser focos de una determinada faceta, en la taxonomía común. Así por ejemplo el aislado jugadores, una vez incorporado a la taxonomía común, pasó a ser un foco de la faceta agentes.

\section{Evaluación de las taxonomías particulares}

Finalmente, para cumplir con el Objetivo 3, las 9 taxonomías particulares fueron comparadas con la taxonomía común, identificándose la cantidad de focos en cada una de las facetas.

\section{RESULTADOS}

\section{Identificación de taxones y selección de términos}

Los focos pueden observarse en la Tabla 1. Se presentaron las siguientes situaciones, ordenadas por las categorías del CRG.

- Entidades completas o complejas

Fue necesario elegir entre varios sinónimos. Se prefirió estadio a cancha y a los nombres propios Bombonera, Monumental y Gasómetro. También se prefirió complejos deportivos a instalaciones y a ciudad deportiva, así como museo a vitrina y al nombre propio Museo de la Pasión Boquense. Se eligió el término sedes educativas en lugar de los nombres propios de colegios e institutos dependientes de los clubes. Con el fin de respetar la garantía documental, se eligió shop a pesar de ser un término en lengua inglesa; un sinónimo usado fue store, también en inglés.

- Agentes: individuos, personal, organizaciones

La mayoría de los clubes usaban la expresión El club, que fue el término preferido, aunque dos clubes utilizaban institución e institucional respectivamente. Se prefirió autoridades a comisión, directivos o comisión directiva, así como plantel a equipo, por ser la opción de la mayoría. De nuevo aparece en esta categoría un término en inglés: sponsors.

\section{- Pacientes}

El término hinchada fue usado por la mayoría de los clubes y se eligió para la taxonomía común. Se eliminó el sinónimo pueblo canalla, por la referencia al apodo específico de uno de los clubes.

- Producto final

Fue la categoría con mayor cantidad de focos. Aunque no todas las taxonomías particulares establecían una 
jerarquía entre los focos, nos pareció adecuado hacerlo en la taxonomía común. Así los focos de primer nivel en esa faceta son: deportes, cultura, entretenimiento, prensa, imágenes, emblemas, cantos, enciclopedia, visitas guiadas.

Se prefirió emblemas a símbolos, aunque ambos términos eran usados por varios clubes.

Entre los sinónimos registrados pueden mencionarse imágenes y galería, habiéndose preferido el primero. También se prefirió cantos a cantitos y canciones; wallpapers a afiches (el término en inglés era el más usado) y postales se prefirió a tarjetas. El foco audio y video aparece en algunos clubes dividido en dos taxones diferentes: a) audio, b) video.

\section{- Acciones, actividades}

Varios clubes hacen una diferencia entre campeonato, que se refiere al torneo que se está disputando en el país y competencias que se refiere a otros torneos, por ejemplo las copas internacionales. La palabra torneo se usó como sinónimo de campeonato en algunos clubes. El partido se refiere a la contienda que se desarrolla en una determinada fecha (en la taxonomía común se eliminó el artículo El), mientras que tabla se refiere a presentación de las posiciones y promedios. El foco comunicación abarca una serie de recursos que los clubes ofrecen a sus socios para comunicarse: correo electrónico, chat, foros, encuestas, etc.

- spacio

Los clubes mencionaban solamente al país (Argentina) y a la ciudad en la que están radicados.

- Tiempo

Hay dos manifestaciones temporales: por un lado la Historia, es decir los hechos y personajes más destacados en el pasado del club. Por otro lado el fixture o esquema de partidos del campeonato que se está jugando, ordenado por fechas.

\section{Taxonomía común}

La taxonomía común resultante se muestra en la tabla 1.

Las siguientes categorías no contaron con ningún foco:

- Atributos: propiedades, cualidades, estados, condiciones

- Entidades abstractas

- Entidades que ocurren en la naturaleza
TABLA 1

Taxonomía común a clubes de fútbol argentinos

\begin{tabular}{|c|c|}
\hline Categorías del CRG & $\begin{array}{c}\text { Taxones identificados } \\
\end{array}$ \\
\hline $\begin{array}{l}\text { Entidades completas o } \\
\text { complejas }\end{array}$ & $\begin{array}{l}\text { Estadio } \\
\text { Sede social } \\
\text { Complejos deportivos } \\
\text { Museo } \\
\text { Sedes educativas } \\
\text { Store }\end{array}$ \\
\hline $\begin{array}{l}\text { Agentes: individuos, } \\
\text { personal, organizaciones }\end{array}$ & $\begin{array}{l}\text { Club } \\
\text { Autoridades } \\
\text { Filiales } \\
\text { Colaboradores } \\
\text { Sponsors } \\
\text { Plantel } \\
\text { - Jugadores } \\
\text { - Goleadores } \\
\text { - Idolos } \\
\text { Cuerpo técnico } \\
\text { Promesas } \\
\end{array}$ \\
\hline Pacientes & $\begin{array}{l}\text { Socios } \\
\text { Hinchada } \\
\text { Agrupaciones } \\
\text { Comunidad }\end{array}$ \\
\hline Productos finales & 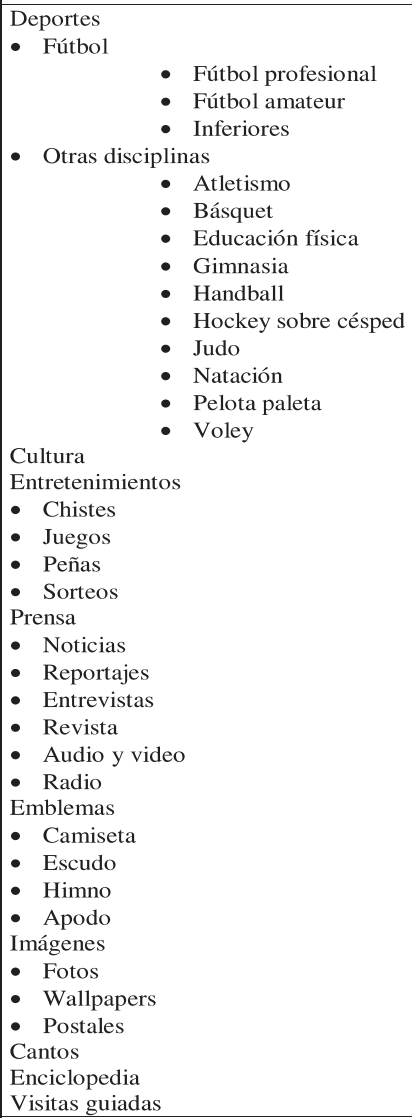 \\
\hline \multirow[t]{2}{*}{ Acciones, actividades } & $\begin{array}{l}\text { Campeonato } \\
\text { - El partido }\end{array}$ \\
\hline & $\begin{array}{l}\text { - Tabla } \\
\text { Competencias } \\
\text { Comunicación } \\
\text { Relaciones públicas }\end{array}$ \\
\hline Espacio & $\begin{array}{l}\text { Argentina } \\
\text { Ciudad de Buenos Aires } \\
\text { La Plata } \\
\text { Avellaneda } \\
\text { Rosario }\end{array}$ \\
\hline Tiempo & $\begin{array}{l}\text { Historia } \\
\text { - Fundación, nacimiento y desarrollo } \\
\text { - Títulos, copas } \\
\text { - Campañas } \\
\text { - Anécdotas } \\
\text { - Leyendas } \\
\text { Fixture }\end{array}$ \\
\hline
\end{tabular}


- Entidades u organismos vivos

- Artefactos hechos por el hombre

- Sustancias materiales o constituyentes

- Partes o componentes

- Agentes: equipamiento, aparatos

\section{Evaluación de taxonomías particulares}

TABLA 2

Distribución de focos por categorías en las distintas taxonomías

\begin{tabular}{l|c|c|c|c|c|c|c|c|c|c}
\hline \multirow{2}{*}{ Categorías del CRG } & \multicolumn{7}{c}{ Número de focos en cada taxonomía } \\
\cline { 2 - 11 } & Común & a & b & c & d & e & f & g & h & i \\
\hline Entidades completas o complejas & 6 & 1 & 3 & 2 & 2 & 4 & 3 & 2 & 3 & 4 \\
Agentes: individuos, personal, etc. & 11 & 5 & 4 & 2 & 6 & 5 & 4 & 6 & 3 & 3 \\
Pacientes & 4 & 2 & 1 & 1 & 1 & 2 & 2 & 2 & 1 & 1 \\
Producto final & 40 & 12 & 7 & 3 & 7 & 6 & 6 & 11 & 11 & 15 \\
Acciones, actividades & 6 & 2 & 1 & 3 & 3 & 1 & 1 & 2 & 2 & 3 \\
Espacio & 5 & 2 & 2 & 3 & 2 & 2 & 2 & 2 & 2 & 2 \\
Tiempo & 7 & 3 & 3 & 4 & 3 & 4 & 2 & 6 & 2 & 3 \\
\hline Total de focos & 79 & 27 & 21 & 18 & 24 & 24 & 20 & 31 & 24 & 31 \\
\hline \% de focos & 100 & 34 & 26 & 22 & 30 & 30 & 25 & 39 & 30 & 39 \\
\hline
\end{tabular}

En la tabla 2 se comparan las taxonomías particulares con la taxonomía común. De los 79 focos de la taxonomía común, las taxonomías particulares coinciden en un rango de $22-39 \%$, es decir ninguna de las taxonomías particulares contempló la totalidad de los focos incluidos en la taxonomía común.

\section{DISCUSIÓN Y CONCLUSIONES}

\section{Identificación de taxones y selección de términos preferidos}

El análisis de los términos usados en las taxonomías particulares indica una cierta tendencia a utilizar expresiones que no responden a las tradicionales normas de control de vocabulario para tesauros y listas de autoridades (13-14). Por ejemplo, el uso del artículo en la expresión El Club o los nombres propios o específicos de cada club, como el ya mencionado pueblo canalla, Museo de la Pasión Boquense, nace la Academia, el león de oro, etc. Todos ellos son términos que intentan comunicar un sentimiento de pertenencia al club y por lo tanto, el profesional que diseñe una taxonomía para este tipo de organizaciones deberá respetarlos.

No es raro encontrar términos en inglés como shop, store, wallpapers, chat, fixture. En este sentido resulta un tanto contradictorio haber hispanizado la palabra inglesa football y recurrir a otros términos en inglés para representar conceptos que cuentan con un equivalente en español, por ejemplo tienda, kiosko, carteles, conversación, cronograma. No obstante, es posible que sean de uso común entre los seguidores de este deporte y por lo tanto, el diseñador de una taxonomía de este tipo deberá tenerlos en cuenta y, en todo caso, aplicar las normas para el tratamiento de los términos prestados, estableciendo las correspondiente relaciones de equivalencia (13-14).
Un análisis más detallado de los términos usados en las taxonomías de clubes de fútbol argentinos ha sido publicado por Caminotti y Martínez (15).

\section{Taxonomía común}

La taxonomía común demuestra, una vez más, que la metodología del análisis por facetas es útil para desarrollar una taxonomía corporativa.

Contando con la información de base, es posible analizarla, seleccionar los aislados y luego organizarlos por categorías o facetas fundamentales. El método además se puede aplicar a cualquier tipo de organización

\section{Evaluación de las taxonomías particulares}

La poca coincidencia entre los taxones de las taxonomías particulares y los focos de la taxonomía común (menos del 40\% en el mejor de los casos, Tabla 2) demuestra que estas taxonomías particulares podrían enriquecerse sustancialmente con un mejor análisis de la información que el club de fútbol puede aportar en su sitio web.

En ese sentido, consideramos que las categorías del CRG resultan una herramienta muy útil para el profesional que diseñe una taxonomía de este tipo de organización, ya que le permite agotar todas las posibilidades de agregar información. Esto se puede apreciar analizando las categorías del CRG que no tuvieron ningún taxón. Por ejemplo, dentro de la categoría entidades abstractas podrían incluirse conceptos como misión, visión, objetivos, estrategias, liderazgo, filosofía del club, etc., que le darían al club una mayor jerarquía como organización.

${ }^{1}$ Las letras identifican a las taxonomías de cada club, según el orden en que se mencionan en la Introducción. 
La categoría partes o componentes podría aplicarse en la subdivisión de otras facetas, como la de entidades completas o complejas, mientras que artefactos hechos por el hombre y agentes: equipamiento, aparatos, seguramente contarían con taxones si los sitios estudiados hubieran sido más exhaustivos en su análisis de la información que deben comunicar.

Como señalan Argudo y Centelles (16), una taxonomía corporativa debe basarse en el contexto, es decir conectar a las personas, la organización y la información de la manera más efectiva. En ese sentido, el método del análisis por facetas resulta aún más conveniente, ya que de acuerdo con los principios del CRG, no es obligatorio completar todas las categorías recomendadas, ni tampoco limitarse a ellas, es decir pueden implementarse otras categorías según se requiera para cada caso en particular, con lo cual ofrece una gran flexibilidad.

\section{AGRADECIMIENTO}

Este trabajo ha sido subsidiado por el Programa de Incentivos del Ministerio de Educación, Ciencia y Tecnología de la Nación. Proyecto acreditado 11/H361.

Artigo submetido em 02/01/2006 e aceito em 23/02/2007.

\section{REFERENCIAS}

1. FOSKETT, Antony C. Subject approach to information. $5^{\text {th }}$ ed. London: Library Association, 1996.

2. TAYLOR, Arlene G. The organization of information. $2^{\text {nd }}$ ed. Westport: Libraries Unlimited, 2004. (Library and information science text series).

3. RANGANATHAN, Shiyali R. Prolegomena to library classification. $3^{\text {rd }}$ ed. Bombay: Publication House, 1967.

4. VICKERY, Brian C. Faceted classification: a guide to construction and use of special schemes. London: Aslib, 1960.

5. AITCHISON, Jean; GILCHRIST, Alan; BOWDEN, David. A guide for thesaurus construction. $4^{\text {th }}$ ed. London: Aslib, 2000.
6. BARITÉ ROQUETA, Mario G. La noción de categoría y sus implicaciones en la construcción y evaluación de lenguajes documentales. In: LÓPEZ HUERTAS, María José; FERNÁNDEZMOLINA, Juan Carlos (Ed). CONGRESO ISKO-ESPAÑA EOCONSID'99, 4., 1999, Granada. La representación y organización del conocimiento en sus distintas perspectivas: su influencia en la recuperación de la información: actas... Granada: Universidad de Granada, 1999.

7. GILCHRIST, Alan; KIBBY, Peter. Taxonomies for business: access and connectivity in a wired World. London: TFPL, 2000.

8. CONWAY, Susan; SLIGAR, Char. Unlocking knowledge assets. Redmon: Microsoft Press, 2002. cap. 6, p. 105-124.

9. ELLIS, David; VASCONCELOS, Ana. Ranganathan and the net: using facet analysis to search and organise the world wide web. Aslib proceedings, v. 51, n. 1, p. 3-10, 1999.

10. BROUGHTON, Vanda. Facet analytical theory as a basis for a knowledge organization tool in a subject portal. In: ISKO CONFERENCE, 7., 2002, Granada, Spain. Challenge in knowledge representation and organization for the $21^{\text {st }}$ century: proceedings... Würzburg: Ergon Verlag, 2002. (Advances in knowledge organization, 8). Disponível em: <http://www.ucl.ac.uk/fatks/paper2.htm>. Acesso em: 04 dez. 2005.

11. TUDHOPE, Douglas. Representation and retrieval in faceted systems. In: ISKO CONFERENCE, 7., 2002, Granada, Spain. Challenge in knowledge representation and organization for the $21^{\text {st }}$ century: proceedings... Würzburg: Ergon Verlag, 2002. (Advances in knowledge organization, 8). Disponível em: <http://www.glam.ac.uk/soc/research/ hypermedia/publications/presentationdocs/ISKOn.doc $>$. Acesso em: 05 dez. 2005.

12. MARTÍNEZ, Ana et al. Las categorías o facetas fundamentales: una metodología para el diseño de taxonomías corporativas de sitios web argentinos. Ciência da Informação, v. 33, n. 2, p. 106-111, 2004. Disponível em: < http://www.scielo.br/pdf/ci/v33n2/a11v33n2.pdf>. Acesso em: 04 dez. 2005.

13. INTERNATIONAL

ORGANIZATION

FOR

STANDARDIZATION - ISO. Documentation: guidelines for the establishment and development of monolingual thesauri. Geneva, 1986. (ISO 2788: 1986).

14. FEDERAÇÃO INTERNACIONAL DE ASSOCIAÇÕES E INSTITUIÇÕES BIBLIOTECÁRIAS - IFLA. Directrices para las autoridades de materia. Madrid: ANABAD, 1995.

15. CAMINOTTI, María Laura; MARTíNEZ, Ana María. Fútbol, tesauros y taxonomías web: un desafío para el control del vocabulario. Información, Cultura y Sociedad, n. 14, p. 73-81, 2006.

16. ARGUDO, Silvia; CENTELLES, Miguel. Metodología para el diseño de taxonomías corporativas. Investigación Bibliotecológica, v. 19, n. 39, p. $158-177,2005$. 